\title{
Exemplary medicine: why doctors should practise what they preach
}

\author{
John Fletcher MB BChir MPH
}

See also the article by Frank and colleagues on page 649 and at www.cmaj.ca/lookup/doi/10.1503/cmaj.121028 and the article by Redelmeier and colleagues on page E337 and at www.cmaj.ca/lookup/doi/10.1503/cmaj.122047

$\mathrm{T}$ here can be many good reasons why the care patients receive varies, but when there is no good reason, such differences are unfair. Research in this issue of $C M A J$ gives 2 examples of unfair differences in care for which doctors themselves can take responsibility. ${ }^{1,2}$

Using routine health information systems covering roughly half of Israel's population, Frank and colleagues ${ }^{1}$ compared the preventive health care habits of physicians and their patients. They found that a higher percentage of patients received a specific preventive measure if their doctor had received the same measure than if their doctor had not. For example, $49 \%$ of patients who were eligible received flu vaccination if their doctor had also received flu vaccination, but only $43 \%$ of eligible patients received the vaccination if their doctor had not. Perhaps doctors who have had flu vaccinations are just more interested in prevention across the board? Apparently not, because the rates of mammography were the same among patients of doctors who did or did not receive the flu vaccination. Conversely, $70 \%$ of eligible patients received a mammogram if their doctor had received one, but only $66 \%$ received a mammogram if their doctor had not. These associations appeared to be specific for each preventive measure examined in this study.

One might argue that the percentage differences in preventive health care are modest because they only amount to a few percent. However, many patients decide whether to have a flu vaccination quite independently of what their personal doctor might think. Some patients simply book a visit to a nurse or vaccination clinic each year, and some have no intention of ever having a flu vaccination because they do not believe that it works well enough. It is only among patients who are unsure that a doctor is likely to influence the decision. The $6 \%$ or so differences among all patients may reflect a much larger proportion of those who were unsure. In that context, the effects reported by Frank and colleagues $^{1}$ seem quite important and suggest that doctors' own health-seeking behaviour influences the advice and care they give to their patients.

Do the results of a study in Israel have any relevance in Canada? Personally, I think they do. But if you think that doctors in Canada practise in a very different way than they do in Israel, or if you think that patients make choices about preventive health care in a very different way, then a dose of skepticism is reasonable.

A second research article ${ }^{2}$ in this issue suggests that, in another context and country, doctors' attitudes affect their prac- tice. Redelmeier and colleagues ${ }^{2}$ examined organ donation rates in hospitals across Ontario. Patients who die in almost any hospital in well-populated areas of Ontario could become organ donors. The logistics of harvesting and transport are not insurmountable, especially for large hospitals in urban areas near transplant centres. What their research showed, though, was that donor rates per 100 deaths were 4 times higher in hospitals with transplant programs than in large general hospitals without such programs. It is difficult to believe that such a large difference could be due to differences in case mix or donor suitability. It is far more likely that doctors in transplant centres counsel patients and their families in ways that are different from those who are more distanced from the practice. Hospital culture and the example that other doctors set is likely influencing practice.

In both of these examples, the advice that patients or their families received differed not because of their needs but because of their doctors' behaviours or attitudes. Because this is unfair, we should pay more attention to doctors' personal health practices and to professional culture. There are 10 provincial physician health programs in Canada, as well as the Canadian Medical Association's own, each providing help and support when physicians run into health problems. Canada has an annual conference on physician health, and the next one is this fall in Calgary, Alberta. As a profession, we should work with these organizations to broaden the scope of physician health beyond illness. Individually, doctors can "try harder," but as a group we should take action to change professional culture. Doctors should be encouraged to reflect on how their attitudes and behaviours may influence the care they give. Because it is good medical practice, this encouragement should be part of continuing medical education and become part of our professional standards so that physicians can advise their patients with commitment and integrity.

\section{References}

1. Frank E, Dresner Y, Shani M, et al. The association between physicians' and patients' prevention practices. CMAJ 2013;185:649-53.

2. Redelmeier D, Markel F, Scales DC. Organ donation after death in Ontario. CMAJ 2013;185:659.

Competing interests: See www.cmaj.ca/site/misc/cmaj_staff.xhtml

Affiliations: See www.cmaj.ca/site/misc/cmaj_staff.xhtml

Correspondence to: $C M A J$ editor, pubs@cmaj.ca

CMAJ 2013. DOI:10.1503/cmaj.130514 